\title{
NOVA LEI DOS PORTOS: DESAFIOS JURÍDICOS E PERSPECTIVAS DE INVESTIMENTOS*
}

\author{
Ana Claudia Farranha, Conrado da Silveira Frezza \\ e Fabiana de Oliveira Barbosa \\ NEW LAW OF PORTS: LEGAL CHALLENGES \\ AND INVESTMENT PROSPECTS
}

\section{RESUMO}

A SITUAÇÃO DOS PORTOS BRASILEIROS TEM SIDO IDENTIFICADA COMO UM DOS PRINCIPAIS ENTRAVES PARA O DESENVOLVIMENTO ECONÔMICO DO BRASIL. ATRIBUI-SE ESSE PROBLEMA, PREPONDERANTEMENTE, AOS ALTOS CUSTOS E À POUCA EFICIÊNCIA NAS OPERAÇÕES PORTUÁRIAS. RECENTEMENTE, COM A EDIÇĀO DA NOVA LEI DOS PORTOS, FOI ESTABELECIDO UM NOVO MARCO REGULATÓRIO PARA O SETOR PORTUÁRIO BRASILEIRO, BUSCANDO DAR MAIOR AGILIDADE ÀS TRANSAC̄ÕES E MODERNIZAR O SETOR. OS ARRENDAMENTOS PORTUÁRIOS PASSARAM A SER REGULADOS DE FORMA SEMELHANTE A UMA CONCESSÃO DE SERVIÇO PÚBLICO, ENFATIZANDO-SE PARÂMETROS DE DESEMPENHO E A REGULAÇÃO TARIFÁRIA. A NOVA LEGISLACÃO TRAZ IMPORTANTES INOVAÇÕES, COMO O CRITÉRIO DE JULGAMENTO NAS LICITAÇÕES DE ARRENDAMENTOS, A NÃO OBRIGATORIEDADE DE PAGAMENTO DE VALOR DE OUTORGA PARA A ASSUNÇÃO DAS ÁREAS E A MAIOR FACILIDADE PARA O ESTABELECIMENTO DE PORTOS PRIVADOS. O OBJETIVO DESTE ARTIGO É INVESTIGAR OS PRINCIPAIS DESAFIOS JURÍDICOS TRAZIDOS POR ESSAS INOVACÕES E COMO ELAS SE ADEQUAM À ESTRUTURA REQUERIDA PARA UM MELHOR FUNCIONAMENTO DOS PORTOS E PARA AS PERSPECTIVAS DE INVESTIMENTOS NO SETOR. INICIALMENTE, SERÁ ABORDADO O PROCESSO DE CONVERSÃO DA MP N. 595/2012 NA LEI N. 12.815/2013, ENFATIZANDO OS PRINCIPAIS PONTOS DE DEBATE E INTERESSES EM JOGO QUE MOTIVARAM AS ALTERAÇÕES AO PROJETO DE LEI NA FASE DO VETO PRESIDENCIAL. EM SEGUIDA, SERÁ INVESTIGADA A NATUREZA

\section{ABSTRACT}

THE SITUATION OF THE BRAZILIAN PORTS HAS BEEN IDENTIFIED AS A MAJOR CONSTRAINT TO ECONOMIC DEVELOPMENT IN BRAZIL. THIS PROBLEM IS ATTRIBUTED MAINLY TO THE HIGH COSTS AND LOW EFFICIENCY IN PORT OPERATIONS. RECENTLY, WITH THE ENACTMENT OF THE NEW LAW OF PORTS, IT WAS ESTABLISHED A NEW REGULATORY FRAMEWORK FOR THE BRAZILIAN PORT SECTOR, AIMING TO PROVIDE GREATER FLEXIBILITY TO THE TRANSACTIONS AND MODERNIZE THE SECTOR. PORT LEASES WILL BE REGULATED SIMILARLY TO A PUBLIC SERVICE CONCESSION, EMPHASIZING PERFORMANCE PARAMETERS AND TARIFF REGULATION. THE NEW LEGISLATION BRINGS IMPORTANT INNOVATIONS, SUCH AS THE CRITERION OF JUDGMENT IN BIDDING FOR LEASES, THE NOT MANDATORY PAYMENT OF GRANT VALUE FOR THE ASSUMPTION OF THE AREAS AND THE FACILITATION FOR ESTABLISHING PRIVATE PORTS. THE AIM OF THIS PAPER IS TO INVESTIGATE THE MAIN LEGAL CHALLENGES BROUGHT BY THESE INNOVATIONS AND HOW THEY CONFORM TO THE REQUIRED STRUCTURE FOR A BETTER FUNCTIONING OF PORTS AND THE PROSPECTS OF INVESTMENT IN THE SECTOR. INITIALLY, WE WILL ADDRESS THE PROCESS OF CONVERSION FROM MP NO. 595/2012 TO LAW No. 12.815/2013, EMPHASIZING THE MAIN POINTS OF DEBATE AND THE INTERESTS AT STAKE THAT MOTIVATED CHANGES TO THE BILL DURING THE VETO. THEN WE WILL INVESTIGATE THE LEGAL STATUS OF PORT LEASES, 
JURÍDICA DOS ARRENDAMENTOS PORTUÁRIOS, ANALISANDO EM QUE MEDIDA ELES SE APROXIMAM DO MODELO DE CONCESSÕES DE SERVIÇOS PÚBLICOS. NO ITEM SEGUINTE, SERÃO APONTADAS AS MODIFICAÇÕES NA COMPETÊNCIA DO PODER CONCEDENTE E DOS DEMAIS ENTES ENVOLVIDOS NA REGULAÇÃO DO SETOR PORTUÁRIO. SERÃO ANALISADAS, AINDA, AS MUDANÇAS NO CRITÉRIO DE JULGAMENTO DAS LICITAÇÕES DOS ARRENDAMENTOS E SEUS PRINCIPAIS IMPACTOS. POR FIM, SERÃO FEITAS ALGUMAS OBSERVAC̣ÕES A RESPEITO DA SITUAÇÃO DOS TERMINAIS DE USO Privativo. Concluiu-Se que a nova LeI dos Portos, ALÉM DE CONFERIR AOS ARRENDAMENTOS PORTUÁRIOS O MESMO TIPO DE REGULAÇÃO TÍPICA DA CONCESSÃO DE SERVIÇOS PÚBLICOS, TAMBÉM PRIORIZA A AGILIDADE E O BAIXO CUSTO DAS OPERAÇÕES, TRAZENDO PERSPECTIVAS DE CRESCIMENTO PARA O SETOR, EMBORA SEU IMPACTO EXATO SEJA INCERTO. O CAMPO DE ESTUDO É O DIREITO REGULATÓRIO E O MÉTODO UTILIZADO FOI O INDUTIVO.

PALAVRAS-CHAVE

SETOR PORTUÁRIO; NOVA LEI DOS PORTOS; REGULAC̣Ão; CONCESSÃO PÚBLICA; ARRENDAMENTOS PORTUÁRIOS.

\begin{abstract}
ANALYZING THE EXTENT TO WHICH THEY APPROACH THE PUBLIC SERVICE CONCESSIONS MODEL. IN THE NEXT ITEM, WE WILL PRESENT THE CHANGES IN THE COMPETENCE OF THE GRANTING AUTHORITY AND OTHER ENTITIES INVOLVED IN THE REGULATION OF THE PORT SECTOR. WILL BE FURTHER ANALYZE THE CHANGES IN THE CRITERIA FOR JUDGING THE BIDS IN PORT LEASES AND ITS MAJOR IMPACTS. FINALLY, WE WILL MAKE SOME OBSERVATIONS REGARDING THE STATUS OF PRIVATE TERMINALS. WE CONCLUDE THAT THE NEW LAW OF PORTS ATTRIBUTES TO PORT LEASES THE SAME KIND OF REGULATION TYPICAL OF PUBLIC SERVICE CONCESSIONS, AND EMPHASIZES AGILITY AND THE LOW COST OF OPERATIONS, BRINGING GROWTH PROSPECTS TO THE SECTOR, ALTHOUGH ITS EXACT IMPACT IS UNCERTAIN. THE FIELD OF STUDY OF THIS ARTICLE IS REGULATORY LAW AND ITS METHOD WAS THE INDUCTIVE.
\end{abstract}

\section{KEYWORDS}

PORT SECTOR; NEW LAW ON PORTS; REGULATION; PUBLIC CONCESSION; PORT LEASES.

\section{INTRODUÇÃO}

O desenvolvimento econômico dos países tem como um de seus pressupostos a expansão e a prosperidade do comércio internacional. As políticas voltadas ao setor portuário desempenham, nesse sentido, um papel estratégico na conjuntura econômica brasileira. Sabe-se que o setor portuário constitui-se atualmente como um dos principais gargalos do comércio internacional no Brasil, sobretudo em razão dos altos custos e a pouca eficiência nas operações portuárias.

No intuito de corrigir essa situação, o marco regulatório do setor portuário brasileiro passou por diversas modificações nas últimas décadas, com destaque para a edição da Lei n. 8.630/1993 (Lei de Modernização dos Portos) e do Decreto n. 6.620/2008, sobre diretrizes para o desenvolvimento e o fomento do setor de portos e terminais portuários. Essas normas introduziram significativas mudanças no setor, especialmente no que diz respeito ao uso e à administração dos portos, à movimentação de carga e aos contratos de arrendamento.

A Lei n. 8.630/1993 foi promulgada com o objetivo de tornar os portos mais ágeis e competitivos frente ao mercado internacional, uma vez que os custos operacionais eram muito superiores aos praticados no exterior. Por meio dessa lei, em seu art. $1^{\circ}, \S 2^{\circ}$, praticamente todos os serviços e estruturas até então operados pelo Poder Público (seja na esfera federal, estadual ou municipal) tiveram sua prestação delegada à iniciativa privada, por meio de licitação, ficando este apenas com a administração/gestão e com papel de autoridade portuária, conforme o art. 33 da referida lei. 
A Lei de Modernização dos Portos teve, então, quatro pilares básicos: ampliação do direito da iniciativa privada em realizar as operações portuárias (art. $1^{\circ}$ ); criação do Órgão Gestor da Mão de Obra (OGMO) (art. 18); criação da Administração Portuária (art. 33); e a instituição do Conselho da Autoridade Portuária (CAP) (art. 30), dividida em três grupos: poder público, operadores portuários e trabalhadores portuários.

Dentre as modalidades possíveis de transferências da operação das áreas portuárias públicas para o setor privado, destaca-se a de arrendamentos de áreas e instalações portuárias, onde a exploração das atividades portuárias ocorre após seleção por meio de licitação nas modalidades de concorrência ou leilão, conforme o art. $4^{\circ}$, I, da Lei n. 8.630/1993.

Essas mudanças determinaram uma nova organização administrativa para o setor portuário que, em observância às novas diretrizes ditadas para o setor, no exercício da sua competência institucional, adotou como principais objetivos da sua gestão: (i) conceder a operação portuária e o arrendamento de áreas portuárias, gerando recursos para o governo; (ii) incentivar a concorrência entre os portos e terminais, de modo a reduzir custos e obter maior eficiência; e (iii) acabar com o monopólio dos trabalhadores portuários.

Quanto às competências da administração portuária sob a égide da Lei n. 8.630/1993, destacam-se as atribuições conferidas pelo art. 33, § $1^{\circ}$, para normatizar (incisos I, II, III, IX), fiscalizar (incisos VI, VII), controlar (incisos XI, XII, e art. 39), bem como realizar a exploração comercial do porto (arts. $4^{\circ}$, I; 33, $\S 1^{\circ}$, IV; e 34). A administração do porto é a pessoa jurídica responsável pela exploração comercial do porto organizado, encarregada de realizar “[...] uma atividade de gestão portuária, que abrange diversos patamares de competência executiva, como a prestação de serviços portuários (art. $9^{\circ}, \S 3^{\circ}$ da LP) e outros que devem ser transferidos a terceiros" (BESERRA, 2005, p. 118).

Mais de uma década após a edição da Lei n. 8.630/1993, entrou em vigor o Decreto n. 6.620 , de 29 de outubro de 2008, que dispõe sobre políticas e diretrizes para o desenvolvimento e o fomento do setor de portos e terminais portuários de competência da Secretaria de Portos da Presidência da República, disciplina a concessão de portos, o arrendamento e a autorização de instalações portuárias marítimas.

O objetivo desse decreto era consolidar o marco regulatório vigente na época, estabelecido pela Lei de Modernização dos Portos, e ao mesmo tempo inovar, abrindo possibilidades não contempladas no texto legal que o referido decreto regulamenta.

De modo geral, o Decreto n. 6.620/2008 definiu três possibilidades de participação de entes públicos ou privados no fomento e desenvolvimento dos portos nacionais: (i) concessão de portos organizados por meio de licitação, destacando-se que qualquer interessado na exploração do serviço poderá, mediante concessão, requerer à Agência Nacional de Transporte Aquaviário (ANTAQ) a abertura do respectivo processo licitatório (art. 15); (ii) arrendamento de instalações portuárias mediante 
licitação, desde que integrantes do Plano Geral de Outorgas e do Programa de Arrendamento do Porto, conforme disposto no art. 25, § $1^{\circ}$, do Decreto n. 6.620/2008, destacando-se que a ampliação de área arrendada somente será permitida em área contígua e quando comprovada a inviabilidade técnica, operacional e econômica de realização de licitação para novo arrendamento; e (iii) autorização para construção e exploração de instalação portuária de uso privativo. Neste ponto, o decreto ratificou que os terminais privativos deverão operar precipuamente com as cargas próprias de seu proprietário e, residualmente, com as cargas de terceiros (art. 35).

Apesar de as modificações trazidas pelas normas mencionadas terem buscado aprimorar e dinamizar a atividade portuária, verifica-se, ainda, muitos aspectos deficientes no setor. A dificuldade, o custo e o tempo para a realização de operações indicam que, após 16 anos da edição da Lei n. 8.630/1993, continuaram a existir significativos problemas estruturais a serem resolvidos.

A par dessa situação, o Tribunal de Contas da União (TCU) realizou um diagnóstico da situação dos portos no Acórdão n. 1.904/2009, sobre planejamento portuário e sustentabilidade financeira das autoridades portuárias, e no Acórdão n. 2.896/2009, sobre processos de arrendamento e concorrência. Nesses estudos, foram avaliados os entraves à expansão e à modernização da infraestrutura do segmento portuário, sob a perspectiva da atração de investimentos. O Acórdão n. 1.904/2009-Plenário, em seu item 383-A, tratou do planejamento do setor e da sustentabilidade financeira das Companhias Docas, deliberando à Secretaria de Portos da Presidência da República (SEP/PR): desenvolver normativo para regulamentação do Plano de Desenvolvimento e Zoneamento (PDZ), de forma a ter maior utilidade e padronização, bem como orientar as autoridades portuárias na promoção de programas de arrendamento e promover o saneamento financeiro, profissionalizar a gestão e aumentar a governança corporativa das administrações portuárias.

Em relação à ANTAQ, o acórdão, em seu item 383-B, definiu que a ela caberia estabelecer regras claras para a revisão e o reajuste das tarifas portuárias com base em estudos fundamentados sobre os custos das administrações portuárias, prevendo mecanismos para compartilhar com os usuários os benefícios gerados com possíveis aumentos de eficiência, prezando pela modicidade tarifária e pelo equilíbrio econômico-financeiro das administrações portuárias. Por fim, no item 383-C, deliberou à SEP/PR e à ANTAQ elaborar, conjuntamente, mecanismos regulatórios que permitissem a implementação de sistemas de preços e tarifas com base em centros de custos e que incentivem a busca da eficiência operacional pelas administrações portuárias.

Em suma, esses estudos do TCU indicaram à época que, muito embora as mudanças introduzidas pela Lei n. 8.630/1993 tenham buscado implementar uma gestão privada às atividades operacionais, ainda havia grandes dificuldades por parte das autoridades portuárias para suprir as necessidades dos operadores e usuários. 
Com a edição da Medida Provisória n. 595, de 6 de dezembro de 2012, convertida na Lei n. 12.815, de 5 de junho de 2013, foi estabelecido um novo marco regulatório para o setor portuário brasileiro. Um dos seus objetivos principais foi proporcionar mais agilidade e modernizar o setor, reduzindo os custos das transações. Nesse sentido, a nova legislação dos portos traz importantes inovações, que serão abordadas posteriormente com mais detalhes neste artigo.

Para efeito de comparação entre os diplomas legais, destaca-se o Quadro 1 (ao final do artigo), explicitando-se algumas das principais mudanças entre a Lei n. 8.630/1993 e a Lei n. 12.815/2013, e também analisando a MP n. 595/2013 e suas modificações no Projeto de Lei de Conversão n. 9/2013. Como se pode constatar deste quadro, a edição da MP n. 595/2012 e sua posterior conversão na Lei n. 12.815/2013 alteraram significativamente a modelagem das concessões e arrendamentos nos portos organizados brasileiros. Dentre as alterações, destacam-se a caracterização jurídica dos arrendamentos como concessão de uso de bem público (conforme Exposição de Motivos da MP n. 595/2012) e a sua aproximação com o instituto da concessão de serviço público. Assim, além da cobrança de parâmetros de desempenho, foram estabelecidos metas e prazos para o alcance de níveis de serviço. Além disso, o novo modelo estabelece: regulação da tarifa cobrada; alterações de competências do Poder Concedente e demais entes envolvidos; mudança no critério de julgamento das licitações; e, ainda, modificações na caracterização de terminais de uso privativo.

\section{Conversão dA MP N. 595/20I2 NA LeI N. I 2.815/2013 - Alterações APÓS A FASE DE VETO PRESIDENCIAL}

Desde sua entrada em vigor, a MP n. 595/2012 trouxe diversas discussões e debates que envolvem ideias e interesses divergentes de diversos atores do setor portuário. Desde trabalhadores da Guarda Portuária até as próprias autoridades portuárias sentiram suas competências diminuídas em relação à SEP/PR e à ANTAQ. Muitos arrendatários também se sentiram prejudicados pelas determinações da referida MP, uma vez que ela obrigava a licitação de diversas áreas que estavam com contratos vencidos ou vincendos, contrariando os interessados no prolongamento desses arrendamentos.

Após a fase de emendas no Congresso Nacional e do veto presidencial, a MP n. 595/2012 foi convertida na Lei n. 12.815/2013, a nova Lei dos Portos. Os principais vetos da Presidente referiram-se a dispositivos que tratavam da renovação e da prorrogação de concessões de portos, bem como da garantia de concorrência que o novo marco regulatório pretende implementar. A fase de vetos expressa concepções e interesses divergentes dos atores envolvidos no sistema portuário, por isso, é interessante a sua análise.

Segundo a Ministra-Chefe da Casa Civil à época (Sra. Gleisi Hoffman), os vetos foram feitos para assegurar o objetivo principal da lei, que é garantir a abertura e a 
competitividade do setor e afastar qualquer insegurança jurídica. Os principais vetos presidenciais são descritos a seguir.

Art. $2^{\circ}$, VIII e alíneas: foi excluída a definição de “terminal indústria”, tipo de instalação portuária localizada fora da área do porto organizado e explorada mediante autorização. Este veto visa acabar com a distinção entre carga própria e de terceiros. $\mathrm{Na}$ avaliação do governo, a restrição da utilização de um terminal apenas para carga própria reduziria a competitividade e poderia travar o setor.

Art. $5^{\circ}, \S 1^{\circ}$ : este dispositivo previa a prorrogação automática dos contratos de concessão e arrendamento. O Congresso havia retirado do texto a expressão segundo a qual a prorrogação seria realizada "a critério do Poder Concedente". Com o veto, as prorrogações deixam de ser automáticas e os contratos de concessão e arrendamento ficam sem prazo definido. Nas razões do veto, a Presidente alega que a modificação feita pelo Congresso "retira do Poder Executivo a prerrogativa de avaliar a conveniência e a oportunidade de cada prorrogação, prejudicando sua capacidade de planejamento e gestão do setor portuário e violando o princípio constitucional da separação dos poderes".

Art. 56, caput e parágrafo único: esses dispositivos previam a prorrogação de contratos de concessão e arrendamento celebrados antes da Lei n. 8.630/1993, o que permitia a continuidade de diversos contratos que já estavam vencidos e não abria espaço para novas licitações. Na justificativa do veto, a Presidente argumentou que o texto "extrapola os termos dos contratos de arrendamento vigentes" e tenta estabelecer "salvaguardas contra a ampliação do setor" para os terminais que já estão em funcionamento, inviabilizando o aumento da concorrência no setor.

Art. $57, \S \S 2^{\circ}$ e $4^{\circ}$ : foram vetadas disposições a respeito da prorrogação antecipada dos contratos de arrendamento firmados sob a vigência da Lei n. 8.630/1993.

Art. 69: esse artigo previa que concessões e permissões mencionadas na Lei n. 9.074/95, ainda vigentes, poderiam ser prorrogadas até atingir o prazo de 25 anos, contados da data de assinatura do respectivo instrumento concessório, podendo ser prorrogado por 5 anos. Com o veto presidencial, não poderá haver a prorrogação desses contratos.

\section{NATUREZA JURÍdiCA DOS ARRENDAMENTOS PORTUÁRIOS}

Os portos organizados do Brasil possuem funções muito mais abrangentes do que o mero suporte para o atracamento de navios. Há, nos portos, grandes áreas destinadas à prestação de serviços das mais diversas naturezas, que vão desde atividades bancárias até o embarque e desembarque de mercadorias, manutenção de contêineres, entre outras. Estes dois últimos são exemplos de atividades prestadas nas áreas e instalações portuárias operacionais, que são aquelas destinadas à movimentação e à armazenagem de cargas e ao embarque e desembarque de passageiros. ${ }^{1}$ Empresas privadas ocupam essas áreas operacionais por meio de contratos de arrendamentos portuários. $\mathrm{O}$ 
estabelecimento de novos critérios e de uma nova natureza jurídica para os contratos de arrendamentos portuários foi um dos principais aspectos abordados pela nova Lei dos Portos - Lei n. 12.815/2013.

É importante ressaltar que esse novo marco regulatório distingue dois tipos de "outorga"2: de um lado, a concessão do porto organizado como um todo; de outro lado, o arrendamento de áreas dentro do porto organizado. A Exposição de Motivos da MP n. 595/2012, que deu origem à nova Lei dos Portos, refere-se a ambos os institutos como concessão de uso de bem público. No presente artigo, somente será analisada a natureza jurídica dos arrendamentos portuários, buscando-se indicar que, na nova legislação, esses arrendamentos não são meros aluguéis de áreas, mas institutos análogos à concessão de serviços públicos.

$\mathrm{O}$ arrendamento portuário é uma figura típica do direito civil, que estabelece uma figura contratual pela qual o arrendador cede o direito de uso e gozo de uma propriedade imobiliária por certo tempo, mediante o pagamento pelo arrendatário de uma prestação monetária. Respeitada a destinação do imóvel, o arrendatário, em regra, pode explorá-lo da forma que bem entender, usar as técnicas produtivas que achar mais adequadas, atingir o nível de eficiência que conseguir e, se o serviço realizado no imóvel implicar cobrança de tarifas, pode cobrar as tarifas que bem entender. Afinal, o arrendamento é um instituto do direito privado, por isso não cabe ao arrendador interferir na atividade desenvolvida pelo arrendatário, desde que esteja recebendo o valor de arrendamento acordado.

Quando a Lei n. 8.630/1993 instituiu a figura do arrendamento portuário, o modelo de concessões de serviços públicos, apesar de já previsto na Constituição Federal, ainda não tinha regras definidas por legislação específica, o que ocorreu somente após a edição da Lei de Concessões - Lei n. 8.987, de 13 de fevereiro de 1995. Por isso, quando Lei n. 8.630/1993 incorporou a figura do arrendamento, o fez justamente no intuito de preservar os aspectos privados desse instituto. Os arrendatários recebiam o arrendamento mediante pagamento de valor de outorga e, embora houvesse previsão de alguns parâmetros para medir o desempenho do serviço, não havia, por exemplo, controle sobre as tarifas cobradas dos usuários dos serviços prestados nas instalações arrendadas. Em geral, sob a vigência da Lei n. 8.630/1993, os arrendatários possuíam maior liberdade para desenvolver seus serviços utilizando-se das instalações arrendadas dentro do porto.

A Lei n. 12.815/2013 manteve a figura do arrendamento portuário, mas adaptou essa figura à nova realidade jurídica e política vigente. No aspecto jurídico, a referida lei não poderia conceder o uso de bem público sem observar os princípios da Lei de Concessões, que já estava em plena vigência; no aspecto político, o governo estava determinado a incentivar a produtividade e diminuir os custos das operações portuárias. A solução foi manter a figura do arrendamento portuário, mas agregando aspectos que o aproximam a uma concessão de serviço público. 
Nos contratos de arrendamentos portuários conforme a Lei n. 12.815/2013, além da especificação da área ocupada, há, também, a definição e as condições referentes ao serviço a ser prestado (art. $5^{\circ}$, III), já que se trata de um serviço de natureza pública. Serviço público é toda atividade de oferecimento de utilidade ou comodidade material destinada à satisfação da coletividade em geral, que o Estado presta diretamente ou por quem lhe faça às vezes, sob um regime de Direito Público - portanto, consagrador de prerrogativas de supremacia (MELLO, 2004, p. 620). Nos contratos de arrendamento portuário, a utilidade pública encontra-se, sobretudo, no serviço que os arrendatários prestam à sociedade, na movimentação ou armazenagem de carga, exercendo influência direta na economia do país. O TCU já se manifestou diretamente sobre o assunto, afirmando no item 25 do Acórdão n. 2.896/2009 - Plenário, que "no que se refere à operação portuária prestada por meio de arrendamento, trata-se de serviço público".

Pelo fato de o arrendamento portuário tratar-se de um serviço de natureza pública, é preciso atentar para o texto do art. 175 da Constituição Federal, que dispõe:

Art. 175. Incumbe ao Poder Público, na forma da lei, diretamente ou sob regime de concessão ou permissão, sempre através de licitação, a prestação de serviços públicos.

Parágrafo único. A lei disporá sobre:

I - o regime das empresas concessionárias e permissionárias de serviços públicos, o caráter especial de seu contrato e de sua prorrogação, bem como as condições de caducidade, fiscalização e rescisão da concessão ou permissão;

II - os direitos dos usuários;

III - política tarifária;

IV - a obrigação de manter serviço adequado.

A prestação de serviços públicos, realizada no intuito de suprir as necessidades coletivas variadas, é uma atividade atribuída precipuamente ao Estado. Em certos casos específicos, entretanto, a execução desses serviços pode ser transferida a particulares, desonerando o ente público de atividades em relação às quais não tem condições financeiras ou entende não ser conveniente prestar diretamente (ARAGÃO, 2009 , p. 1). A parceria entre o Poder Público e a iniciativa privada, na construção e operação de infraestruturas de natureza pública, realiza-se por concessão, ${ }^{3}$ que é situação semelhante ao que ocorre nos casos dos contratos de arrendamento portuário, segundo o novo marco regulatório.

Conforme o referido dispositivo constitucional, a concessão deve ser realizada por licitação pública, promovida pelo órgão regulador e preservando-se os direitos dos usuários, as políticas tarifárias, entre outras garantias. Mediante a concessão, a prestação do serviço "é transferida a um agente privado que se remunerará, via de regra, 
pelas tarifas que os usuários lhe pagarão em razão da fruição do serviço, mantendo o Estado a titularidade e os controles públicos sobre ele” (ARAGÃO, 2009, p. 1). O serviço público prestado na área arrendada é de titularidade do Estado. Isso significa que, mesmo concedendo o serviço, ocorre apenas a transferência de sua prestação, de sua execução, mas o Estado continua com a prerrogativa de estabelecer parâmetros para o seu controle e regulação, além de poder retomar a prestação do serviço se assim considerar necessário. A concessão de serviço público está definida no art. $2^{\circ}$, II, da Lei n. 8.987/1995. De acordo com o Professor Alexandre Santos de Aragão, concessão de serviço público é:

A delegação contratual e remunerada da execução de serviço público a particular para que por sua conta e risco o explore de acordo com as disposições contratuais e regulamentares por determinado prazo, findo o qual os bens afetados à prestação do serviço, devidamente amortizados, voltam ou passam a integrar o patrimônio público. (ARAGÃO, 2009, p. 3)

A Lei n. 8.987/1995 (Lei de Concessões do Serviço Público), estabelece regras sobre a fiscalização do poder concedente, necessidade de serviço adequado aos usuários, encargos da concessionária, política tarifária, normas para a licitação, necessidade de contrato, entre outras. Destaca-se, da lei mencionada, a disposição segundo a qual as concessões deverão sujeitar-se à fiscalização pelo poder concedente responsável pela delegação $\left(\operatorname{art} .3^{\circ}\right.$ ), e também a regra dispondo que toda concessão pressupõe a prestação de serviço adequado ao pleno atendimento dos usuários, definido como aquele que satisfaz as condições de regularidade, continuidade, eficiência, segurança, atualidade, generalidade, cortesia na sua prestação e modicidade das tarifas $\left(\operatorname{art} .6^{\circ}\right)$. Por fim, salienta-se que a concessão deverá ser formalizada obrigatoriamente mediante contrato de concessão (art. $4^{\circ}$ ).

De acordo com Adilson Abreu Dallari (2009, p. 13), o contrato de arrendamento portuário, desde a vigência da Lei n. 8.630/1993, é análogo a um contrato de concessão. Conforme o novo marco regulatório em vigor, o arrendamento portuário é regido por normatização própria, a Lei n. 12.815/2013, aplicando-se, subsidiariamente, a Lei Geral de Licitações (Lei n. 8.666/1993) e a Lei de Concessões de Serviços Públicos (Lei n. 8.987/1995). Nesse sentido, é importante notar que, embora a outorga de instalações portuárias tenha mantido a denominação de "arrendamento" (que é uma figura típica do direito civil), ela possui, de fato, todas as principais características de uma concessão de serviço público. Segundo Marques Neto e Leite:

A caracterização do arrendamento como uma concessão de serviço público considera, em primeiro lugar, que o simples fato do contrato ter o nome de arrendamento não o faz submeter-se, automaticamente, ao regime do 
arrendamento previsto no Código Civil e autorizado por meio do Decreto-lei n. 9.760/46. Em Direito não há palavras mágicas, cujo mero uso teria o condão de dar a natureza dos seres jurídicos. Importa, pois, não o nome que se dê ao negócio jurídico, mas sim a natureza das relações estabelecidas e as consequências que delas advêm. (MARQUES NETO; LEITE, 2003, p. 150)

A diferença entre a denominação de um instituto jurídico e suas características de fato também é abordada por Meirelles, que explica que a chamada "locação" do bem público nada mais é do que uma concessão:

A locação é contrato típico do Direito Privado, onde as partes devem manter equivalência de situações nos direitos e obrigações que reciprocamente assumirem. Por isso se conceitua a locação como um contrato bilateral perfeito, oneroso, comutativo e consensual. Ora, no Direito Administrativo jamais se poderá transpassar o uso e gozo do bem público com as características da locação civil, porque implicaria renúncia de poderes irrenunciáveis da Administração, para que ela viesse a se colocar em igualdade com o particular, como é da essência desse contrato no campo do Direito Privado. O só fato de uma lei administrativa, primando pela falta de técnica, referir-se erroneamente a um instituto civil não é o bastante para implantá-lo em nosso Direito Público. [...] O que a lei federal denominou impropriamente de "locação" nada mais é que concessão remunerada de uso dos bens de domínio público patrimonial, instituto, esse, perfeitamente conhecido e praticado pela Administração Pública dos povos cultos e regido por normas próprias do Direito Administrativo. (MEIRELLES, 2000, p. 479)

É possível concluir, portanto, que embora o direito portuário vigente forneça uma caracterização sui generis para a delegação das instalações portuárias, que são tratadas como "arrendamentos", isso não significa que a nova Lei dos Portos esteja em desacordo com o sistema jurídico vigente, isto é, com o modelo de concessões de serviços públicos. Apesar de ser o arrendamento um instituto típico do direito privado, os arrendamentos portuários funcionam da mesma forma que uma concessão de serviço público, em que o poder concedente não só tem a possibilidade de regular a tarifa praticada (por meio do critério de julgamento da licitação), como também estabelece parâmetros para avaliação de desempenho, além de metas e prazos para o alcance de níveis de serviço.

Se os arrendatários terão, por um lado, de praticar tarifa regulada e cumprir metas de desempenho, por outro lado, terão a segurança fornecida pelo contrato de arrendamento que, no caso, se equipara a um contrato de concessão, que não é precário, pois, 
caso seja rescindido pelo Poder Público antes da amortização dos investimentos, conferirá ao investidor direito a indenização.

Os contratos de arrendamento portuário são fiscalizados pela ANTAQ, e deverão seguir as diretrizes da Secretaria de Portos da Presidência da República (SEP/PR), conforme será mais bem explicado no próximo tópico. Dessa forma, o arrendamento portuário não é caracterizado como um mero aluguel de instalações públicas, mas como um instituto efetivamente regido pelo modelo de concessão de serviços públicos, conforme estabelecido no art. 175 da Constituição Federal. Isso garante a participação da iniciativa privada na execução de serviços de natureza pública e, ainda, um maior controle do Estado sobre o serviço prestado.

\section{Poder concedente e Alterações de Competências dos demais ENTES ENVOLVIDOS}

Antes de indicar as alterações de competências das instituições envolvidas com o setor portuário brasileiro trazidas pela Lei n. 12.815/2013, vale elucidar o significado da expressão "poder concedente". O Estado, quando realiza uma concessão, age por meio de um ente federativo - União, Estado, Distrito Federal ou Município -, que, no ato da concessão, é chamado de Poder Concedente. No caso em questão, o Poder Concedente é a União. No setor portuário, a União atua por meio da SEP/PR, portanto, quando a Lei n. 12.815/2013 menciona o Poder Concedente, está se referindo, na verdade, à SEP/PR.

Feita essa ressalva, ressalta-se outra mudança fundamental trazida pela Lei n. 12.815/2013, que diz respeito a alterações nas competências dos entes envolvidos nas concessões e arrendamentos portuários.

De acordo com o novo marco regulatório, o Poder Concedente, representado pela SEP/PR, fica responsável por elaborar o planejamento setorial em conformidade com as políticas e diretrizes de logística integrada, bem como definir as diretrizes para a realização dos procedimentos licitatórios, inclusive para os respectivos editais e instrumentos convocatórios, conforme previsto no art. 16, I e II, da Lei n. 12.815/2013. Trata-se da prerrogativa de implementar políticas públicas, sendo possível afirmar, nesse sentido, que a SEP é responsável, basicamente, pelo plano estratégico do setor portuário.

Já à ANTAQ compete, entre outras atribuições, a elaboração do edital de licitação para a concessão de serviços portuários e arrendamento, bem como a realização do procedimento licitatório - com base nas diretrizes definidas pela SEP/PR -, conforme previsto no art. $6^{\circ}, \S \S 2^{\circ}$ e $3^{\circ}$, da Lei n. 12.815/2013. Essas atribuições podem ser entendidas como estando no plano tático do setor portuário.

Por fim, compete à administração do porto organizado, denominada autoridade portuária, as atribuições previstas nos arts. 17 e seguintes da Lei n. 12.815/2013. 
Fica a autoridade portuária, incluindo-se nesse grupo as Companhias Docas, incumbida de atribuições referentes ao plano gerencial, desenvolvendo atividades como a arrecadação dos valores das tarifas relativas às suas atividades e a fiscalização de obras de construção e da operação portuária.

\section{Mudança no CRitério de JUlgamento das licitações}

Um esforço no sentido de modernizar as atividades portuárias está presente na mudança do critério de julgamento das licitações introduzida pela Lei n. 12.815/2013, que altera a sistemática de funcionamento dos arrendamentos portuários no sentido de exigir dos arrendatários serviços mais eficientes e com menores tarifas em vez de exigir a cobrança de valor de outorga.

Primeiramente, nota-se que "tarifa", nesse contexto, refere-se ao valor pago à arrendatária pelo usuário em razão dos serviços prestados nos terminais, e diferencia-se do valor pago periodicamente pela arrendatária à administração portuária em razão do uso da infraestrutura comum do porto.

Dito isso, cumpre observar que, na vigência da Lei n. 8.630/90, o critério de julgamento nas licitações de arrendamento portuário era a “maior oferta”, em que a licitante vencedora era aquela que oferecia ao Poder Concedente o maior valor de outorga, ou seja, que pagasse o maior valor ao Estado para assumir o arrendamento. Conforme o novo marco regulatório, porém, não há mais a obrigatoriedade de pagamento de valor de outorga. Os novos critérios de julgamento foram citados no art. $6^{\circ}$ da Lei n. 12.815/2013:

Art. $6^{\circ}$ Nas licitações dos contratos de concessão e arrendamento, serão considerados como critérios para julgamento, de forma isolada ou combinada, a maior capacidade de movimentação, a menor tarifa ou o menor tempo de movimentação de carga, e outros estabelecidos no edital, na forma do regulamento.

A escolha pelo critério de capacidade de movimentação, menor tarifa ou menor tempo de movimentação de carga, em vez da obrigatoriedade do pagamento de valor de outorga, parece funcionar como um instrumento de política econômica, que busca responder aos questionamentos colocados à atividade portuária, em cenário em que a franca expansão da atividade pode representar um instrumento para a ampliação do investimento no setor.

\section{Terminais de USO PRIVATIVO}

Outra inovação do novo marco regulatório diz respeito à maior facilidade para o estabelecimento de terminais de uso privativo (TUPs). Antes, era possível somente 
adquirir o direito de uso para terminais de uso privativo se o operador comprovasse a preponderância de movimentação de carga própria; agora, a possibilidade de implementação dos TUPs foi facilitada, já que não há mais o critério de preponderância de carga própria.

A Portaria n. 110 da Secretaria de Portos disciplina as hipóteses de dispensa de emissão de nova autorização para instalações portuárias como TUPs, e estabelece os procedimentos para solicitação de alteração do tipo de carga e/ou ampliação da área da instalação portuária, localizada fora da área do porto organizado. Assim, é dispensável a emissão de nova autorização para os pedidos de alteração do tipo de carga e/ ou ampliação da área da instalação portuária, localizada fora da área do porto organizado, que não exceda a $25 \%$ da área original da instalação portuária. Considera-se "tipo de carga" a especificidade do perfil de carga a ser movimentada e "perfil de carga" aquele classificado conforme uma ou mais das modalidades granel sólido, granel líquido e gasoso, carga geral ou carga conteinerizada.

Já os interessados em ampliar as áreas das instalações portuárias localizadas fora da área do porto organizado, e que não excedam a 25\% das áreas originais, deverão formalizar pedido junto à ANTAQ, mediante a apresentação de documentação específica.

Durante o Breakbulk South America, realizado em São Paulo, durante o ano de 2013, o superintendente de portos da ANTAQ afirmou que o novo desenho dos portos favorece a atração de investimentos privados em larga escala para o setor. Dados recentes mostram que existem atualmente 130 requerimentos para construção e operação de instalações portuárias privadas na Agência, o que totaliza cerca de R \$ 54 bilhões em investimentos. A meta da Agência é dar andamento a 50\% dos pedidos de novas instalações privadas até o final de 2014. Há certames licitatórios de 160 arrendamentos a serem concluídos nos próximos dois anos a três anos e a adaptação de mais de 140 contratos de adesão de instalações portuárias privadas. Em relação ao planejamento, o superintendente de portos da ANTAQ lembrou que há muito o governo vem buscando viabilizar a ampliação da oferta de infraestrutura portuária do país, destacando a importância do Programa Nacional de Dragagem, que a partir da nova legislação dos portos entra na sua segunda fase, e citou como exemplo do planejamento do governo na área o Plano Geral de Outorgas para o setor portuário (PGO dos Portos), elaborado pela ANTAQ, e que atualmente está sob a competência da Secretaria de Portos (ANTAQ, 2013).

Assim, questiona-se se essa maior liberdade para a existência de terminais de uso privativo, que se aproxima da tendência internacional, poderia realmente contribuir para ampliação dos investimentos nos Portos do Brasil. A intenção do Executivo, autor da MP n. 595/2012, que deu origem à nova Lei dos Portos, parece ter sido facilitar a criação de terminais privados para reforçar e dinamizar a atividade por tuária. Há, porém, o risco de se afastar investimentos dos portos públicos, levando-os 
ao sucateamento. Será preciso observar o impacto dessa mudança a partir dos próximos arrendamentos para que se possa avaliar os efeitos dessa flexibilização dos TUPs.

\section{CONSIDERAÇÕES FINAIS}

Os esforços no sentido de modernizar a atividade portuária brasileira por meio da edição da Lei n. 8.630/1993 e do Decreto n. 6.620/2008, embora tenham trazidos melhorias significativas ao setor, não se mostraram suficientes para atender completamente à contínua expansão da demanda da atividade portuária e, consequentemente, da economia brasileira.

No sentido de dinamizar e dar maior eficiência às atividades do setor portuário, foi editada a MP n. 595/2012, posteriormente transformada na Lei n. 12.815/2013, a nova Lei dos Portos. Durante o processo legislativo de conversão da medida provisória em lei, houve alterações significativas após a fase de veto presidencial. Digna de nota foi a alteração, feita pelo Senado e posteriormente vetada pela Presidente, em relação à necessidade de novas licitações para os arrendamentos portuários. De acordo com a concepção original do Executivo, autor da referida MP, deveriam ser realizadas novas licitações no intuito de renovar não apenas os arrendatários mas também as regras dos arrendamentos, de modo a revitalizar e dar maior eficiência às atividades portuárias. As modificações feitas na referida MP na fase de emendas pelo Senado haviam retirado essa necessidade de se realizar novas licitações para os arrendamentos portuários, porém o veto presidencial restabeleceu essa obrigatoriedade das licitações, o que pode ser interpretado como um ponto positivo para a dinamização da atividade portuária.

A Lei n. 12.815/2013 enquadrou o arrendamento portuário de forma análoga à concessão de serviços públicos. Os arrendamentos portuários não apenas serão licitados como também deverão observar estritos parâmetros de avaliação de desempenho. Essa aproximação do arrendamento portuário de uma concessão permite um maior controle do Estado sobre a atividade realizada no porto. Assim, a perspectiva parece ser a de atrair investimentos para o setor portuário e, ao mesmo tempo, planejar de maneira mais uniforme a atividade, respondendo aos questionamentos acerca da eficiência e do desenvolvimento colocados à questão.

A redefinição de competências das instituições envolvidas no setor portuário também é uma inovação importante trazida pela Lei n. 12.815/2013. A maior centralização das atividades nos entes federais - SEP/PR e ANTAQ - permite uma maior coordenação das atividades referentes às novas licitações e auxilia na padronização do sistema de arrendamentos entre os portos brasileiros.

A Lei n. 12.815/2013 inovou, também, no critério de julgamento de licitação dos novos arrendamentos portuários. Ao definir como critério de julgamento, de forma isolada ou combinada, a maior capacidade de movimentação, a menor tarifa ou o menor 
tempo de movimentação de carga, e outros estabelecidos no edital, a referida lei priorizou maior quantidade e preço referentes ao serviço prestado pelo arrendatário, indo ao encontro das necessidades apresentadas ao setor portuário.

Por fim, a facilitação de abertura de TUPs traz novas possibilidades de investimentos privados no setor. Se os portos públicos não atendem às demandas do mercado, haverá a possibilidade de os terminais privados absorverem essa demanda. De um lado, essa flexibilização pode agravar a situação dos portos públicos, já que muitos investimentos serão redirecionados aos portos privados; por outro lado, a abertura de TUPs oferece novas estruturas para a atividade portuária, que podem mostrar-se em um futuro próximo como essenciais para a atividade portuária e, consequentemente, para a economia brasileira.

Há, ainda, muitos desafios a serem superados em relação ao novo marco regulatório do setor portuário. A Lei n. 12.815/2013 definiu claramente os critérios de arrendamentos de áreas afetas à operação portuária; contudo, não definiu diretrizes detalhadas para a licitação das áreas dentro do porto não afetas à operação. É o caso dos terminais cuja destinação não é a operação portuária em si (movimentação e armazenagem de cargas ou embarque e desembarque de passageiros), mas outras atividades, como o suporte à operação (as chamadas "retroáreas") ou os terminais utilizados para atividades industriais. A licitação dessas áreas não possui regulação específica no novo marco regulatório, o que é preocupante, pois muitas vezes os critérios de julgamento para a licitação de áreas operacionais podem ser totalmente descabidos quando aplicados às áreas não operacionais.

Outra questão que merece pesquisas futuras é o fato de o operador portuário poder ser uma pessoa distinta do arrendatário, conforme o art. $2^{\circ}$, XIII, da Lei n. 12.815/2012. Nesse caso, pode acontecer de uma determinada empresa ganhar a licitação de um arrendamento e contratar um operador de sua escolha para realizar a operação em seu lugar, o que, sob a perspectiva de uma concessão tradicional, poderia ser caracterizado como subconcessão, que somente é permitida mediante a realização de outro processo de concorrência pública (art. 26, § $1^{\circ}$, da Lei n. 8.987/1995), que não é exigido no caso dos arrendamentos portuários.

Junto a isso, como sugestão para próximas pesquisas, é importante a investigação sobre a situação jurídica e as consequências advindas da rescisão de contratos de arrendamentos portuários vigentes, celebrados sob a égide de marcos regulatórios anteriores. Muitos desses contratos foram celebrados antes mesmo da Lei n. 8.630/1993, diretamente com as Companhias Docas e sem a exigência de licitação. Assim, a resposta a ser dada pelos tribunais parece ser objeto de análise em trabalhos futuros.

$\mathrm{Na}$ seara dos desafios, cabe destacar aqueles referentes ao modelo de concessão do transporte público no Brasil mencionados pelo TCU em 2007, no trabalho intitulado Desenvolvimento de infraestrutura de transportes no brasil: perspectivas e desafios. Nesse texto, é apontado que grande parte das deficiências encontradas nos trabalhos, editais 
ou projetos analisados pelo TCU está associada à falta de estrutura das instituições, quer seja o órgão executor, as agências reguladoras ou o ministério setorial. Destaca-se, ainda, a necessidade de coordenação institucional entre os órgãos e instituições que atuam no setor de transporte, havendo insuficiência de políticas e diretrizes macrossetoriais e falta de planejamento a longo prazo para o setor de transporte.

E, por fim, outro aspecto relevante citado no documento mencionado acima diz respeito à necessidade de fortalecimento institucional das agências reguladoras, até mesmo no que diz respeito à falta de um quadro de pessoal suficiente, com formação adequada e a remuneração compatível com a complexidade dessas tarefas, para que haja estabilidade no corpo funcional das agências (TCU, 2007, p. 140).

Para que haja um efetivo avanço no funcionamento das atividades desenvolvidas nos portos brasileiros, acompanhado da devida fiscalização por parte dos entes regulatórios, é preciso encontrar respostas para essas e outras questões que continuam a gerar controvérsias no setor. 


\section{Quadro 1 - CoMPARAÇÃo DA LEGISLAÇÃo REFERENTE A institucionalidade dos Portos no Brasil (I993 - 20I2)}

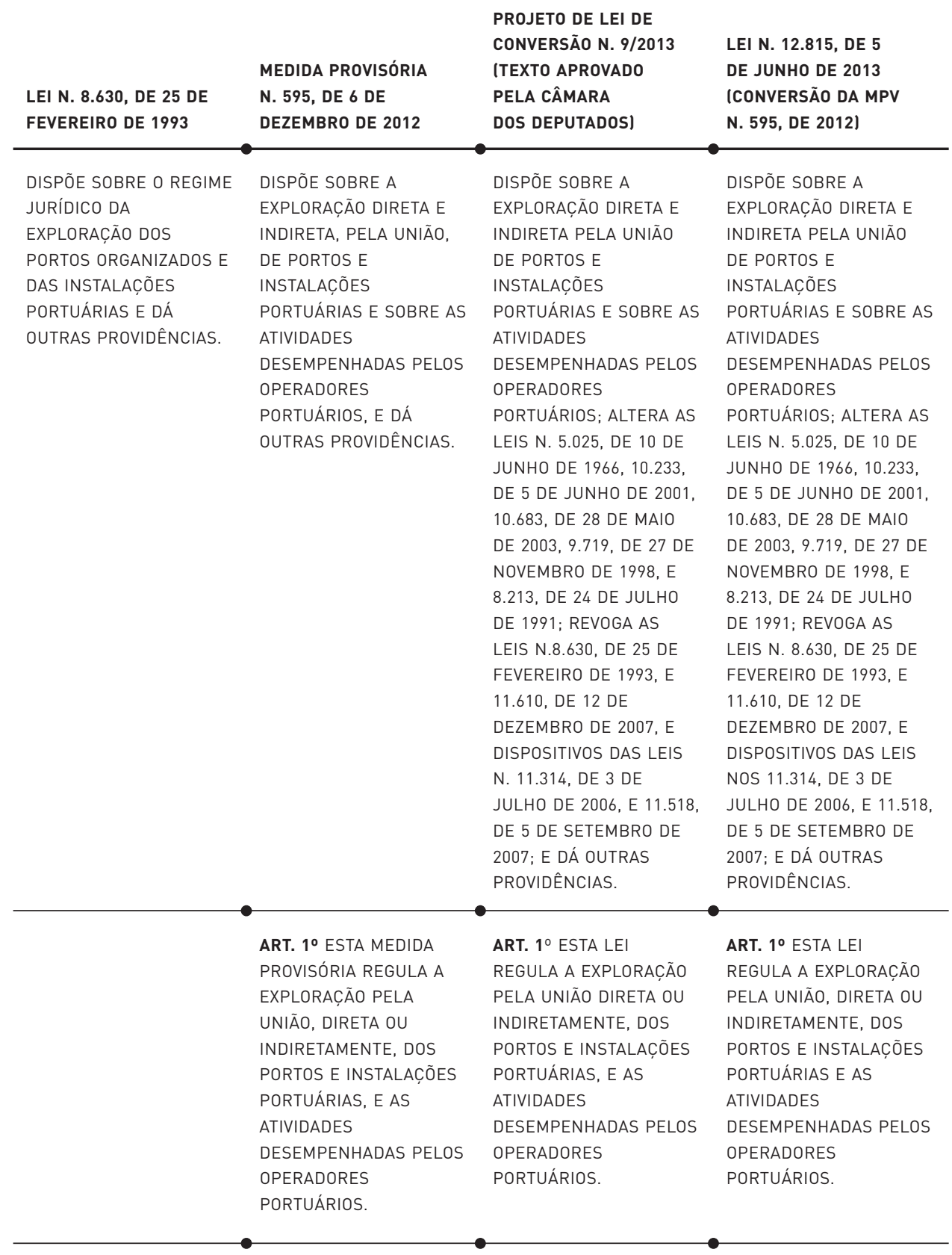




\begin{tabular}{|c|c|c|c|}
\hline ART. $1^{\circ} \mathrm{CABE} \grave{A}$ UNIÃO & $\S 1^{\circ} \mathrm{A}$ EXPLORAÇÃO & $\S 1^{\circ} \mathrm{A}$ EXPLORAÇÃO & $\S 1^{\circ} \mathrm{A}$ EXPLORAÇÃO \\
\hline EXPLORAR, & INDIRETA DO PORTO & INDIRETA DO PORTO & INDIRETA DO PORTO \\
\hline DIRETAMENTE OU & ORGANIZADO E DAS & ORGANIZADO E DAS & ORGANIZADO E DAS \\
\hline MEDIANTE CONCESSÃO, & INSTALAC̣ÕES & INSTALAC̣ÕES & INSTALAC̣ÕES \\
\hline \multirow[t]{24}{*}{ O PORTO ORGANIZADO. } & PORTUÁRIAS NELE & PORTUÁRIAS NELE & PORTUÁRIAS NELE \\
\hline & LOCALIZADAS OCORRERÁ & LOCALIZADAS OCORRERÁ & LOCALIZADAS OCORRERÁ \\
\hline & MEDIANTE CONCESSÃO E & MEDIANTE CONCESSÃO E & MEDIANTE CONCESSÃO E \\
\hline & $\begin{array}{l}\text { ARRENDAMENTO DE BEM } \\
\text { PÚBLICO. }\end{array}$ & $\begin{array}{l}\text { ARRENDAMENTO DE BEM } \\
\text { PÚBLICO. }\end{array}$ & $\begin{array}{l}\text { ARRENDAMENTO DE BEM } \\
\text { PÚBLICO. }\end{array}$ \\
\hline & $\S 2^{\circ} \mathrm{A}$ EXPLORAÇÃO & $\S 2^{\circ} \mathrm{A}$ EXPLORAÇÃO & $\S 2^{\circ} \mathrm{A}$ EXPLORAÇÃO \\
\hline & INDIRETA DAS & INDIRETA DAS & INDIRETA DAS \\
\hline & INSTALAC̣ÕES & INSTALAC̣ÕES & INSTALAC̣ÕES \\
\hline & PORTUÁRIAS & PORTUÁRIAS & PORTUÁRIAS \\
\hline & LOCALIZADAS FORA DA & LOCALIZADAS FORA DA & LOCALIZADAS FORA DA \\
\hline & ÁREA DO PORTO & ÁREA DO PORTO & ÁREA DO PORTO \\
\hline & ORGANIZADO OCORRERÁ & ORGANIZADO OCORRERÁ & ORGANIZADO OCORRERÁ \\
\hline & MEDIANTE & MEDIANTE & MEDIANTE \\
\hline & AUTORIZAÇÃO, NOS & AUTORIZAÇÃO, NOS & AUTORIZAÇÃO, NOS \\
\hline & $\begin{array}{l}\text { TERMOS DESTA MEDIDA } \\
\text { PROVISÓRIA. }\end{array}$ & TERMOS DESTA LEI. & TERMOS DESTA LEI. \\
\hline & $\S 3^{\circ}$ AS CONCESSÕES, OS & $\S 3^{\circ}$ AS CONCESSÕES, OS & $\S 3^{\circ}$ AS CONCESSÕES, OS \\
\hline & ARRENDAMENTOS E AS & ARRENDAMENTOS E AS & ARRENDAMENTOS E AS \\
\hline & AUTORIZAÇÕES DE QUE & AUTORIZAÇÕES DE QUE & AUTORIZAÇÕES DE QUE \\
\hline & TRATA ESTA MEDIDA & TRATA ESTA LEI SERÃO & TRATA ESTA LEI SERÃO \\
\hline & PROVISÓRIA SERÃO & OUTORGADOS A PESSOA & OUTORGADOS A PESSOA \\
\hline & OUTORGADOS A PESSOA & JURÍDICA QUE & JURÍDICA QUE \\
\hline & JURÍDICA QUE & DEMONSTRE & DEMONSTRE \\
\hline & DEMONSTRE & CAPACIDADE PARA SEU & CAPACIDADE PARA SEU \\
\hline & CAPACIDADE PARA SEU & DESEMPENHO, POR SUA & DESEMPENHO, POR SUA \\
\hline & $\begin{array}{l}\text { DESEMPENHO, POR SUA } \\
\text { CONTA E RISCO. }\end{array}$ & CONTA E RISCO. & CONTA E RISCO. \\
\hline$\S 1^{\circ}$ PARA OS EFEITOS & ART. $2^{\circ}$ PARA FINS & ART. $2^{\circ}$ PARA OS FINS & ART. $2^{\circ}$ PARA OS FINS \\
\hline DESTA LEI, & DESTA MEDIDA & DESTA LEI, & DESTA LEI, \\
\hline CONSIDERAM-SE: & $\begin{array}{l}\text { PROVISÓRIA, } \\
\text { CONSIDERAM-SE: }\end{array}$ & CONSIDERAM-SE: & CONSIDERAM-SE: \\
\hline V - INSTALAÇÃO & III - INSTALAC̦ÃO & III - INSTALAC̣ÃO & III - INSTALAC̣ÃO \\
\hline PORTUÁRIA DE USO & PORTUÁRIA - & PORTUÁRIA: INSTALAÇÃO & PORTUÁRIA: INSTALAC̣ÃO \\
\hline PRIVATIVO: A EXPLORADA & INSTALAC̣ÃO LOCALIZADA & LOCALIZADA DENTRO OU & LOCALIZADA DENTRO OU \\
\hline POR PESSOA JURÍDICA & DENTRO OU FORA DA & FORA DA ÁREA DO & FORA DA ÁREA DO \\
\hline DE DIREITO PÚBLICO OU & ÁREA DO PORTO & PORTO ORGANIZADO E & PORTO ORGANIZADO E \\
\hline PRIVADO, DENTRO OU & ORGANIZADO, UTILIZADA & UTILIZADA EM & UTILIZADA EM \\
\hline FORA DA ÁREA DO & EM MOVIMENTAÇÃO DE & MOVIMENTAÇÃO DE & MOVIMENTAÇÃO DE \\
\hline PORTO, UTILIZADA NA & PASSAGEIROS, EM & PASSAGEIROS, EM & PASSAGEIROS, EM \\
\hline MOVIMENTAÇÃO DE & MOVIMENTAÇÃO OU & MOVIMENTAÇÃO OU & MOVIMENTAÇÃO OU \\
\hline PASSAGEIROS OU NA & ARMAZENAGEM DE & ARMAZENAGEM DE & ARMAZENAGEM DE \\
\hline MOVIMENTAC̣ÃO OU & MERCADORIAS, & MERCADORIAS, & MERCADORIAS, \\
\hline ARMAZENAGEM DE & DESTINADOS OU & DESTINADAS OU & DESTINADAS OU \\
\hline MERCADORIAS, & PROVENIENTES DE & PROVENIENTES DE & PROVENIENTES DE \\
\hline DESTINADOS OU & TRANSPORTE & TRANSPORTE & TRANSPORTE \\
\hline
\end{tabular}



TRANSPORTE AQUAVIÁRIO.
PROVENIENTES DE

AQUAVIÁRIO;

AQUAVIÁRIO

AQUAVIÁRIO;

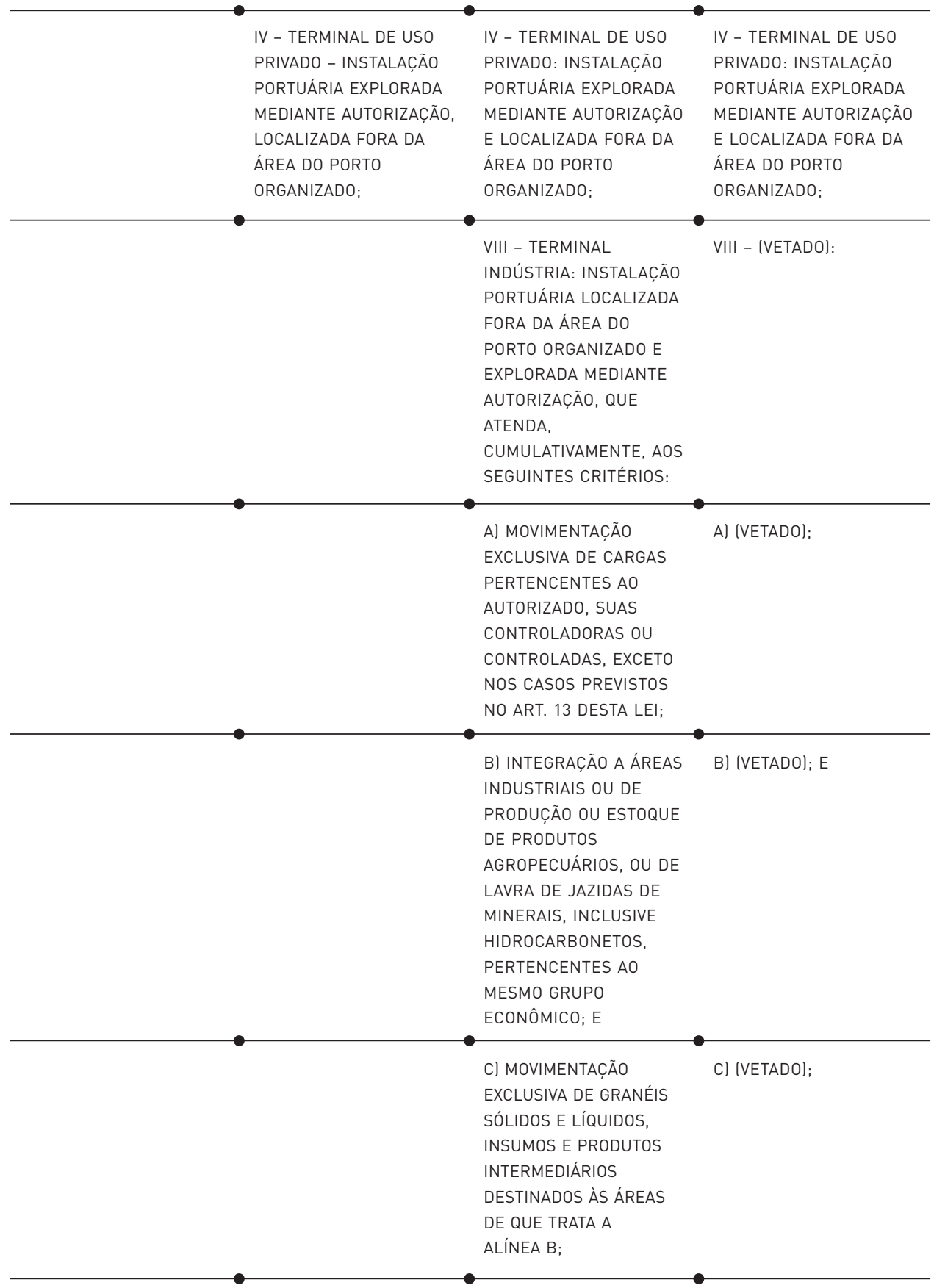




\begin{tabular}{|c|c|c|c|}
\hline$\S 2^{\circ} \mathrm{A}$ CONCESSÃO DO & ART. $4^{\circ} \mathrm{A}$ CONCESSÃO E & ART. $4^{\circ}$ A CONCESSÃO E & ART. $4^{\circ}$ A CONCESSÃO E \\
\hline PORTO ORGANIZADO & O ARRENDAMENTO DE & O ARRENDAMENTO DE & O ARRENDAMENTO DE \\
\hline SERÁ SEMPRE & BEM PÚBLICO & BEM PÚBLICO & BEM PÚBLICO \\
\hline PRECEDIDA DE & DESTINADO À ATIVIDADE & DESTINADO À ATIVIDADE & DESTINADO À ATIVIDADE \\
\hline LICITAÇÃO REALIZADA DE & PORTUÁRIA SERÃO & PORTUÁRIA SERÃO & PORTUÁRIA SERÃO \\
\hline ACORDO COM A LEI QUE & REALIZADOS MEDIANTE & REALIZADOS MEDIANTE & REALIZADOS MEDIANTE \\
\hline REGULAMENTA 0 & A CELEBRAÇÃO DE & A CELEBRAÇÃO DE & A CELEBRAÇÃO DE \\
\hline REGIME DE CONCESSÃO & CONTRATO, SEMPRE & CONTRATO, SEMPRE & CONTRATO, SEMPRE \\
\hline E PERMISSÃO DE & PRECEDIDA DE & PRECEDIDA DE & PRECEDIDA DE \\
\hline \multirow[t]{13}{*}{ SERVIC̣OS PÚBLICOS } & LICITAÇÃO, EM & LICITAÇÃO, EM & LICITAÇÃO, EM \\
\hline & CONFORMIDADE COM & CONFORMIDADE COM O & CONFORMIDADE COM O \\
\hline & O DISPOSTO NESTA & DISPOSTO NESTA LEI E & DISPOSTO NESTA LEI E \\
\hline & MEDIDA PROVISÓRIA E & NO SEU REGULAMENTO. & NO SEU REGULAMENTO. \\
\hline & NO SEU REGULAMENTO. & & \\
\hline & PARÁGRAFO ÚNICO. 0 & & \\
\hline & CONTRATO DE & & \\
\hline & CONCESSÃO PODERÁ & & \\
\hline & ABRANGER, NO TODO OU & & \\
\hline & EM PARTE, A & & \\
\hline & EXPLORAÇÃO DO PORTO & & \\
\hline & ORGANIZADO E SUA & & \\
\hline & ADMINISTRAC̣ÃO. & & \\
\hline
\end{tabular}

ART. $4^{\circ} \ldots$

I - ...

$\S 4^{\circ}$ SÃO CLÁUSULAS ESSENCIAIS NO CONTRATO A QUE SE REFERE O INCISO I DO CAPUT DESTE ARTIGO, AS RELATIVAS:
ART. $5^{\circ}$ SÃO ESSENCIAIS AOS CONTRATOS DE CONCESSÃO E ARRENDAMENTO AS CLÁUSULAS RELATIVAS:
ART. $5^{\circ}$ SÃO ESSENCIAIS AOS CONTRATOS DE CONCESSÃO E ARRENDAMENTO AS CLÁUSULAS RELATIVAS:
ART. $5^{\circ}$ SÃO ESSENCIAIS AOS CONTRATOS DE CONCESSÃO E ARRENDAMENTO AS CLÁUSULAS RELATIVAS:

\begin{tabular}{lll}
\hline III - AOS CRITÉRIOS, & III - AOS CRITÉRIOS, & III - AOS CRITÉRIOS, \\
INDICADORES, & INDICADORES, FÓRMULAS & INDICADORES, FÓRMULAS \\
FÓRMULAS E & E PARÂMETROS & E PARÂMETROS \\
PARÂMETROS & DEFINIDORES DA & DEFINIDORES DA \\
DEFINIDORES DA & QUALIDADE DA ATIVIDADE & QUALIDADE DA ATIVIDADE \\
QUALIDADE DO SERVIÇO; & PRESTADA, ASSIM COMO & PRESTADA, ASSIM COMO \\
& METAS E PRAZOS PARA O & ÀS METAS E PRAZOS \\
& ALCANCE DE & PARA O ALCANCE DE \\
& DETERMINADOS NÍVEIS & DETERMINADOS NÍVEIS \\
& DE SERVIÇO; & DE SERVIÇO; \\
\hline
\end{tabular}

IV - AO VALOR DO CONTRATO, NELE COMPREENDIDA A REMUNERAÇÃO PELO USO DA INFRAESTRUTURA A SER UTILIZADA OU POSTA À DISPOSIÇÃO DA REFERIDA
IV - AO VALOR DO CONTRATO, ÀS TARIFAS PRATICADAS E AOS CRITÉRIOS E PROCEDIMENTOS DE REVISÃO E REAJUSTE;
IV - AO VALOR DO CONTRATO, ÀS TARIFAS PRATICADAS E AOS CRITÉRIOS E PROCEDIMENTOS DE REVISÃO E REAJUSTE;
III - AOS CRITÉRIOS, INDICADORES, FÓRMULAS E PARÂMETROS DEFINIDORES DA QUALIDADE DA ATIVIDADE PRESTADA, ASSIM COMO ÀS METAS E PRAZOS PARA O ALCANCE DE DETERMINADOS NÍVEIS DE SERVICQO;

IV - AO VALOR DO CONTRATO, ÀS TARIFAS PRATICADAS E AOS CRITÉRIOS E PROCEDIMENTOS DE REVISÃO E REAJUSTE; 
INSTALAÇÃO, INCLUSIVE A DE PROTEÇÃO E ACESSO AQUAVIÁRIO;

\begin{tabular}{|c|c|c|c|}
\hline XIV - À OBRIGATORIEDADE & XIV - À OBRIGATORIEDADE & XIV - À OBRIGATORIEDADE & XIV - À OBRIGATORIEDADE \\
\hline DE PRESTAÇÃO DE & DE PRESTAÇÃO DE & DA PRESTAÇÃO DE & DA PRESTAÇÃO DE \\
\hline INFORMAÇÕES DE & INFORMAÇÕES DE & INFORMAÇÕES DE & INFORMAÇÕES DE \\
\hline INTERESSE DA & INTERESSE DO PODER & INTERESSE DO PODER & INTERESSE DO PODER \\
\hline ADMINISTRAC̣ÃO DO & CONCEDENTE, DA & CONCEDENTE, DA & CONCEDENTE, DA \\
\hline PORTO E DAS DEMAIS & AGÊNCIA NACIONAL DE & AGÊNCIA NACIONAL DE & AGÊNCIA NACIONAL DE \\
\hline AUTORIDADES NO PORTO, & TRANSPORTES & TRANSPORTES & TRANSPORTES \\
\hline INCLUSIVE AS DE & AQUAVIÁRIOS - ANTAQ E & AQUAVIÁRIOS - ANTAQ E & AQUAVIÁRIOS - ANTAQ E \\
\hline INTERESSE ESPECÍFICO & DAS DEMAIS & DAS DEMAIS & DAS DEMAIS \\
\hline DA DEFESA NACIONAL, & AUTORIDADES QUE & AUTORIDADES QUE & AUTORIDADES QUE \\
\hline PARA EFEITOS DE & ATUAM NO SETOR & ATUAM NO SETOR & ATUAM NO SETOR \\
\hline \multirow[t]{5}{*}{ MOBILIZAÇÃO; } & PORTUÁRIO, INCLUSIVE & PORTUÁRIO, INCLUSIVE & PORTUÁRIO, INCLUSIVE \\
\hline & AS DE INTERESSE & AS DE INTERESSE & AS DE INTERESSE \\
\hline & ESPECÍFICO DA DEFESA & ESPECÍFICO DA DEFESA & ESPECÍFICO DA DEFESA \\
\hline & NACIONAL, PARA EFEITOS & NACIONAL, PARA EFEITOS & NACIONAL, PARA EFEITOS \\
\hline & DE MOBILIZAC̣ÃO; & DE MOBILIZAC̣ÃO; & DE MOBILIZAC̣ÃO; \\
\hline XVI - AO ACESSO, PELAS & $X V I$ - AO ACESSO AO & XVI - AO ACESSO AO & $X V I$ - AO ACESSO AO \\
\hline AUTORIDADES DO & PORTO ORGANIZADO OU & PORTO ORGANIZADO OU & PORTO ORGANIZADO OU \\
\hline PORTO, ÀS INSTALAC̣ÕES & À INSTALAÇÃO & À INSTALAÇÃO & À INSTALAÇÃO \\
\hline \multirow[t]{6}{*}{ PORTUÁRIAS; } & PORTUÁRIA PELO PODER & PORTUÁRIA PELO PODER & PORTUÁRIA PELO PODER \\
\hline & CONCEDENTE, PELA & CONCEDENTE, PELA & CONCEDENTE, PELA \\
\hline & ANTAQ E PELAS DEMAIS & ANTAQ E PELAS DEMAIS & ANTAQ E PELAS DEMAIS \\
\hline & AUTORIDADES QUE & AUTORIDADES QUE & AUTORIDADES QUE \\
\hline & ATUAM NO SETOR & ATUAM NO SETOR & ATUAM NO SETOR \\
\hline & PORTUÁRIO; & PORTUÁRIO; & PORTUÁRIO; \\
\hline XI - AO INÍCIO, TÉRMINO & $\S 1^{\circ}$ OS CONTRATOS DE & $\S 1^{\circ}$ OS CONTRATOS DE & $\S 1^{\circ}$ (VETADO). \\
\hline E, SE FOR O CASO, ÀS & CONCESSÃO E & CONCESSÃO E & \\
\hline CONDIÇÕES DE & ARRENDAMENTO TERÃO & ARRENDAMENTO TERÃO & \\
\hline PRORROGAC̣ÃO DO & PRAZO DE ATÉ VINTE E & PRAZO DE ATÉ 25 IVINTE E & \\
\hline CONTRATO, QUE PODERÁ & CINCO ANOS, CONTADO & CINCOI ANOS, CONTADO & \\
\hline SER FEITA UMA ÚNICA & DA DATA DA & DA DATA DA ASSINATURA, & \\
\hline VEZ, POR PRAZO MÁXIMO & ASSINATURA, & PRORROGÁVEL UMA ÚNICA & \\
\hline IGUAL AO & PRORROGÁVEL POR NO & VEZ, ATÉ ATINGIR O PRAZO & \\
\hline ORIGINALMENTE & MÁXIMO IGUAL PERÍODO, & MÁXIMO DE 50 & \\
\hline CONTRATADO, DESDE & UMA ÚNICA VEZ, A & (CINQUENTA) ANOS, DESDE & \\
\hline QUE PREVISTA NO & CRITÉRIO DO PODER & QUE O CONCESSIONÁRIO & \\
\hline EDITAL DE LICITAÇÃO E & CONCEDENTE. & OU ARRENDATÁRIO, & \\
\hline QUE O PRAZO TOTAL, & & CONFORME O CASO, & \\
\hline INCLUÍDO O DA & & PROMOVA OS & \\
\hline PRORROGAC̣ÃO, NÃO & & INVESTIMENTOS & \\
\hline EXCEDA A CINQUENTA & & NECESSÁRIOS PARA A & \\
\hline \multirow[t]{4}{*}{ ANOS } & & EXPANSÃO E & \\
\hline & & MODERNIZAÇÃO DAS & \\
\hline & & INSTALAC̣ÕES & \\
\hline & & PORTUÁRIAS. & \\
\hline
\end{tabular}




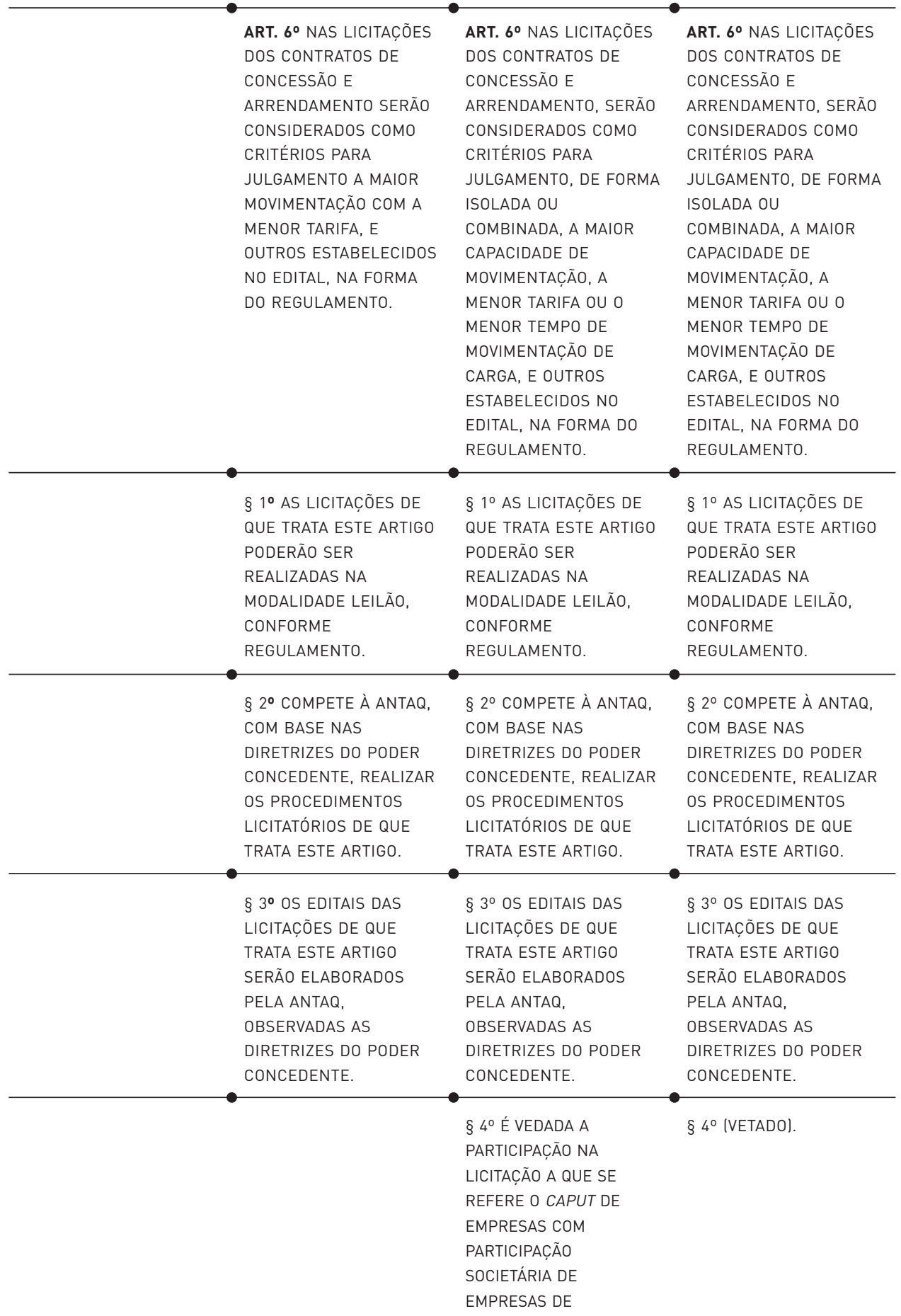




\begin{tabular}{|c|c|c|c|}
\hline & & $\begin{array}{l}\text { NAVEGAÇÃO MARÍTIMA EM } \\
\text { PERCENTUAIS } \\
\text { SUPERIORES A 5\% (CINCO } \\
\text { POR CENTO), EXCLUÍDAS } \\
\text { DESTA VEDAÇÃO AS } \\
\text { EMPRESAS PÚBLICAS, AS } \\
\text { SOCIEDADES DE } \\
\text { ECONOMIA MISTA E SUAS } \\
\text { SUBSIDIÁRIAS. }\end{array}$ & \\
\hline $\begin{array}{l}\text { ART. 34. É FACULTADO O } \\
\text { ARRENDAMENTO, PELA } \\
\text { ADMINISTRAÇÃO DO } \\
\text { PORTO, SEMPRE } \\
\text { ATRAVÉS DE LICITAÇÃO, } \\
\text { DE TERRENOS E } \\
\text { INSTALAÇÕES } \\
\text { PORTUÁRIAS } \\
\text { LOCALIZADAS DENTRO } \\
\text { DA ÁREA DO PORTO, } \\
\text { PARA UTILIZAÇÃO NÃO } \\
\text { AFETA ÀS OPERAÇÕES } \\
\text { PORTUÁRIAS, DESDE } \\
\text { QUE PREVIAMENTE } \\
\text { CONSULTADA A } \\
\text { ADMINISTRAC̣ÃO } \\
\text { ADUANEIRA }\end{array}$ & $\begin{array}{l}\text { ART. 15. A } \\
\text { ADMINISTRAÇÃO DO } \\
\text { PORTO PODERÁ, A } \\
\text { CRITÉRIO DO PODER } \\
\text { CONCEDENTE, EXPLORAR } \\
\text { DIRETA OU } \\
\text { INDIRETAMENTE ÁREAS } \\
\text { NÃO AFETAS ÀS } \\
\text { OPERAÇÕES PORTUÁRIAS, } \\
\text { OBSERVADO O DISPOSTO } \\
\text { NO RESPECTIVO PLANO } \\
\text { DE DESENVOLVIMENTO E } \\
\text { ZONEAMENTO DO PORTO. }\end{array}$ & $\begin{array}{l}\text { ART. 15. ATO DO } \\
\text { PRESIDENTE DA } \\
\text { REPÚBLICA DISPORÁ } \\
\text { SOBRE A DEFINIÇÃO DA } \\
\text { ÁREA DOS PORTOS } \\
\text { ORGANIZADOS, A PARTIR } \\
\text { DE PROPOSTA DA } \\
\text { SECRETARIA DE PORTOS } \\
\text { DA PRESIDÊNCIA DA } \\
\text { REPÚBLICA. }\end{array}$ & $\begin{array}{l}\text { ART. 15. ATO DO } \\
\text { PRESIDENTE DA } \\
\text { REPÚBLICA DISPORÁ } \\
\text { SOBRE A DEFINIÇÃO DA } \\
\text { ÁREA DOS PORTOS } \\
\text { ORGANIZADOS, A PARTIR } \\
\text { DE PROPOSTA DA } \\
\text { SECRETARIA DE PORTOS } \\
\text { DA PRESIDÊNCIA DA } \\
\text { REPÚBLICA. }\end{array}$ \\
\hline & $\begin{array}{l}\text { ART. 18. A SECRETARIA } \\
\text { DE PORTOS DA } \\
\text { PRESIDÊNCIA DA } \\
\text { REPÚBLICA COORDENARÁ } \\
\text { A ATUAÇÃO INTEGRADA } \\
\text { DOS ÓRGÃOS E } \\
\text { ENTIDADES PÚBLICOS } \\
\text { NOS PORTOS } \\
\text { ORGANIZADOS E } \\
\text { INSTALAÇÕES } \\
\text { PORTUÁRIAS, COM A } \\
\text { FINALIDADE DE GARANTIR } \\
\text { A EFICIÊNCIA E A } \\
\text { QUALIDADE DE SUAS } \\
\text { ATIVIDADES, NOS TERMOS } \\
\text { DO REGULAMENTO. }\end{array}$ & $\begin{array}{l}\text { ART. 22. A SECRETARIA DE } \\
\text { PORTOS DA PRESIDÊNCIA } \\
\text { DA REPÚBLICA } \\
\text { COORDENARÁ A ATUAÇÃO } \\
\text { INTEGRADA DOS ÓRGÃOS } \\
\text { E ENTIDADES PÚBLICOS } \\
\text { NOS PORTOS } \\
\text { ORGANIZADOS E } \\
\text { INSTALAÇÕES } \\
\text { PORTUÁRIAS, COM A } \\
\text { FINALIDADE DE GARANTIR } \\
\text { A EFICIÊNCIA E A } \\
\text { QUALIDADE DE SUAS } \\
\text { ATIVIDADES, NOS TERMOS } \\
\text { DO REGULAMENTO. }\end{array}$ & $\begin{array}{l}\text { ART. 22. A SECRETARIA } \\
\text { DE PORTOS DA } \\
\text { PRESIDÊNCIA DA } \\
\text { REPÚBLICA COORDENARÁ } \\
\text { A ATUAÇÃO INTEGRADA } \\
\text { DOS ÓRGÃOS E } \\
\text { ENTIDADES PÚBLICOS } \\
\text { NOS PORTOS } \\
\text { ORGANIZADOS E } \\
\text { INSTALAÇÕES } \\
\text { PORTUÁRIAS, COM A } \\
\text { FINALIDADE DE GARANTIR } \\
\text { A EFICIÊNCIA E A } \\
\text { QUALIDADE DE SUAS } \\
\text { ATIVIDADES, NOS TERMOS } \\
\text { DO REGULAMENTO. }\end{array}$ \\
\hline & $\begin{array}{l}\text { ART. 49. OS CONTRATOS } \\
\text { DE ARRENDAMENTO EM } \\
\text { VIGOR NA DATA DE } \\
\text { PUBLICAÇÃO DESTA } \\
\text { MEDIDA PROVISÓRIA } \\
\text { PERMANECERÃO }\end{array}$ & $\begin{array}{l}\text { ART. 57. OS CONTRATOS } \\
\text { DE ARRENDAMENTO EM } \\
\text { VIGOR FIRMADOS SOB A } \\
\text { LEI N. 8.630, DE } 25 \text { DE } \\
\text { FEVEREIRO DE 1993, QUE } \\
\text { POSSUAM PREVISÃO }\end{array}$ & $\begin{array}{l}\text { ART. 57. OS CONTRATOS } \\
\text { DE ARRENDAMENTO EM } \\
\text { VIGOR FIRMADOS SOB A } \\
\text { LEI N. 8.630, DE } 25 \text { DE } \\
\text { FEVEREIRO DE 1993, QUE } \\
\text { POSSUAM PREVISÃO }\end{array}$ \\
\hline & & & $\begin{array}{l}\text { REVISTA DIREITO GV, SÃO PAULO } \\
11(1) \mid \begin{array}{l}\text { P. } 089-116 \text { | JAN-JUN } 2015\end{array}\end{array}$ \\
\hline
\end{tabular}




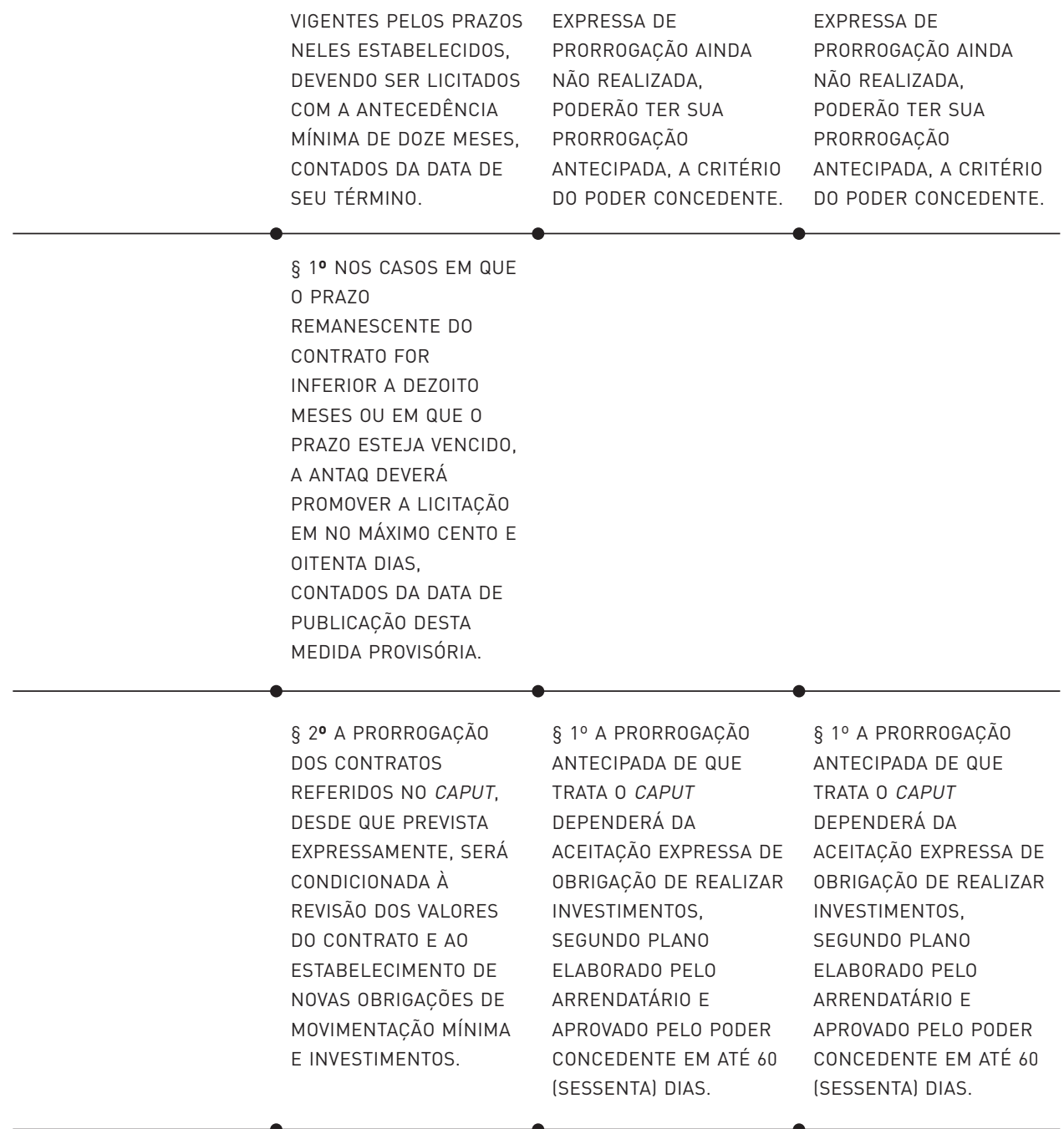

ART. 56. OS CONTRATOS DE ARRENDAMENTO CELEBRADOS ANTERIORMENTE À LEI N. 8.630, DE 25 DE FEVEREIRO DE 1993, DEVERÃO SER RENOVADOS POR MAIS 1 (UM) ÚNICO PERÍODO, NÃO INFERIOR AO PRAZO CONSIGNADO NO RESPECTIVO CONTRATO. 


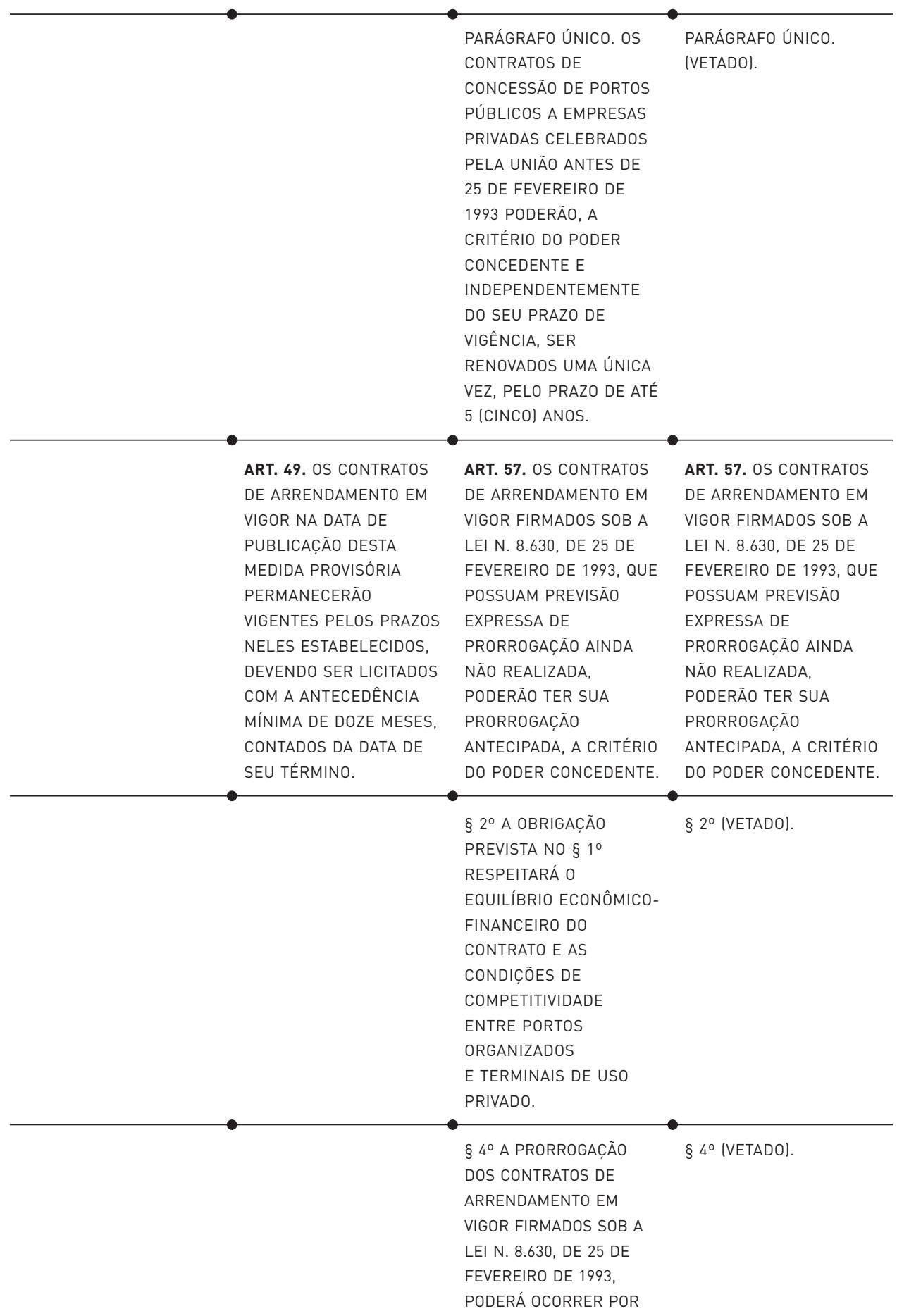


114 : NOVA LEI DOS PORTOS: DESAFIOS JURÍDICOS E PERSPECTIVAS DE INVESTIMENTOS

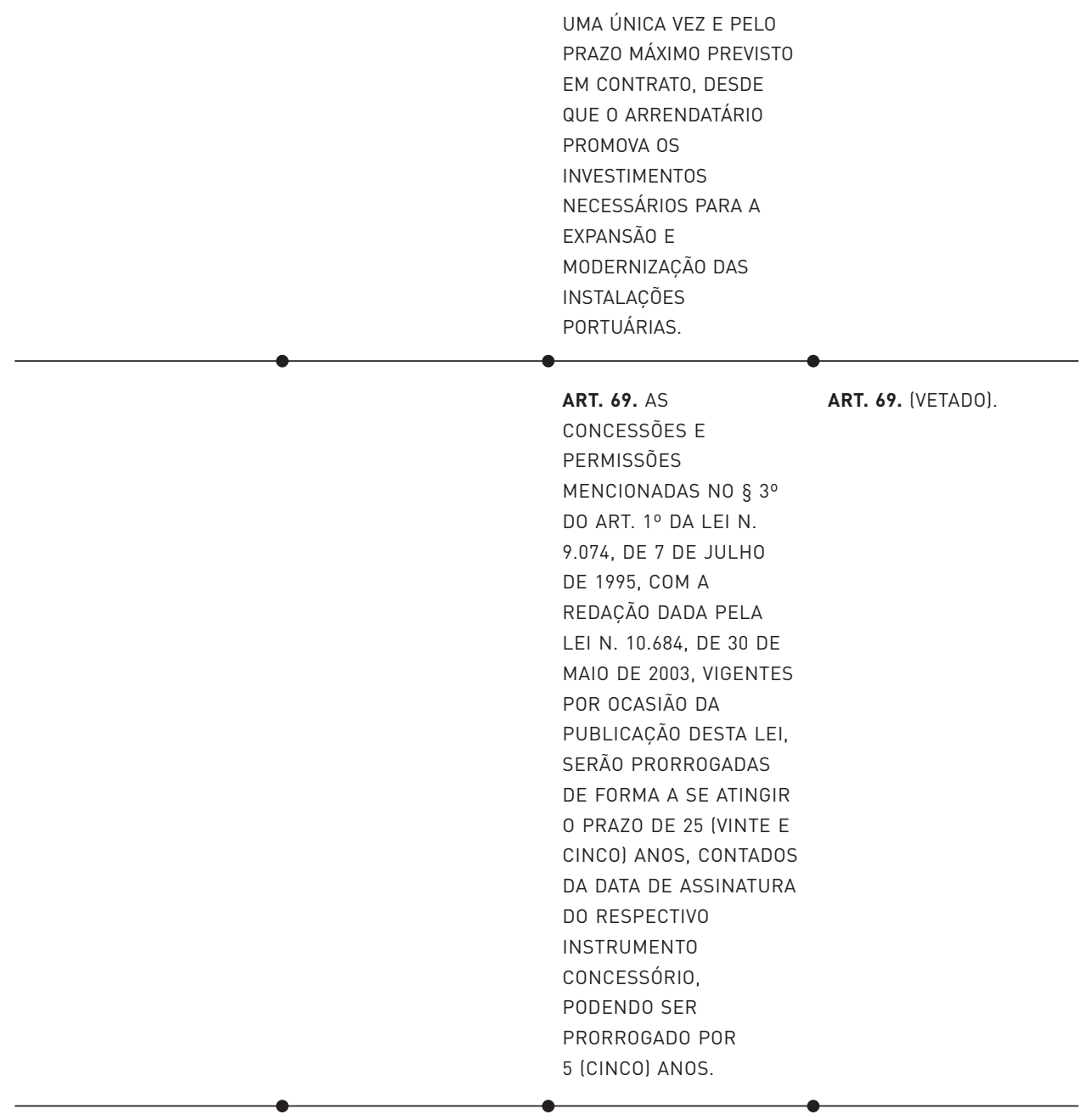




\section{NOTAS}

* Este artigo resulta de projeto de pesquisa desenvolvido junto ao Centro Interdisciplinar de Estudos em Transporte (CFTRU/UnB), sob orientação da Prof. Dra. Ana Claudia Farranha (UnB - Campus Planaltina), financiado com recursos oriundos de cooperação técnica entre a Universidade de Brasília (UnB) e Secretaria de Portos da Presidência da República (SEP/PR).

1 A definição de áreas e instalações portuárias operacionais encontra-se no art. $2^{\circ}$, IV, da Resolução n. 2.240 da ANTAQ.

2 O termo "outorga" costuma ser utilizado com frequência no universo das concessões, porém é preciso ter cuidado com a sua utilização, pois muitas vezes ele é empregado de forma imprecisa. Geralmente, é usado para designar qualquer transferência de serviço público a particular. Isso pode até ser correto se considerarmos o sentido lato da palavra "outorga", como uma entrega, uma transferência. Porém tecnicamente, outorga é uma forma de descentralização da Administração Pública, em que a Administração Pública Direta, por meio de lei própria, institui ou autoriza a criação de ente da Administração Indireta (autarquia, empresa pública, sociedade de economia mista, fundação pública). Na outorga, transfere-se não apenas a prestação do serviço, como nas delegações, mas também a sua titularidade. Já a expressão "valor de outorga" tem outro significado: é um valor ofertado por uma licitante nas licitações para concessão com critério de julgamento "maior oferta” (ver Lei n. 8.987/1995). Diferente, também, é o "Plano de Outorga", que é um documento que relaciona as áreas do porto que serão arrendadas dentro do porto organizado, para uso público, ou autorizadas, no caso de terminais de uso privado.

3 Aqui se deve destacar um debate jurídico em torno do uso do instrumento PPP, conforme apontado pela Lei n. 11.079/2004 para essa modalidade de delegação.

\section{REFERÊNCIAS BIBLIOGRÁFICAS}

AGÊNCIA NACIONAL DE TRANSPORTES AQUAVIÁRIOS. Ruschel: novo marco regulatório atrairá investimentos privados em larga escala para os portos. Disponível em: <http://www.antaq.gov.br>. Acesso em: 6 set. 2013.

ARAGÃO. Alexandre Santos de. Delegações de serviços públicos. Revista eletrônica de Direito Administrativo Econômico, n. 16, nov.-jan. 2009.

BESERRA, Benjamin Gallotti. Ensaio para um compêndio básico de direito portuário. Brasília: Gráfica Alpha, 2005 DALLARI, Adilson Abreu et al. Regulação portuária e concorrência: pareceres jurídicos e econômicos. Abratec, p. 7-47, 2009.

FILHO, Marçal Justen. Teoria geral das concessões de serviço público. São Paulo: Dialética, 2003.

MARQUES NETO, Floriano Azevedo; LEITE, Fábio Barbalho. Peculiaridades do contrato de arrendamento portuário. Revista Trimestral de Direito Público, São Paulo, n. 42, p.142-164, 2003.

MEIRELLES, Hely Lopes. Direito administrativo brasileiro. 25. ed. São Paulo: Malheiros, 2000.

MELlO, Celso Antônio Bandeira. Direito administrativo. 17. ed. São Paulo: Malheiros, 2004.

TRIBUNAL DE CONTAS DA UNIÃO. Acórdão n. 1.904/2009. Plenário. Processo n. 021.200/2008-9.

Relator: Walton Alencar Rodrigues.

Acórdão n. 2.896/2009. Plenário. Processo n. 021.253/2008-2. Relator: Walton Alencar Rodrigues.

Desenvolvimento de Infraestrutura de Transportes no Brasil: Perspectivas e Desafios. Brasília, 2007. 
116 : NOVA LEI DOS PORTOS: DESAFIOS JURÍDICOS E PERSPECTIVAS DE INVESTIMENTOS Brasília - DF - Brasil
anclaudauol.com.br conradodasilveiralagmail.com

$$
\text { (1) }
$$

\section{Ana Claudia Farranha}

Professora adjunta da Faculdade dE DiREITO DA UNIVERSIDADE DE BRASÍLIA (UNB). DOUTORA EM CIÊNCIAS SOCIAIS PELA Universidade ESTADUAL DE CAMPINAS (UnicAmp).

\section{Conrado da Silveira Frezza}

Mestrando em TRANSPORTES PELA UNIVERSIDADE DE BRASílIA (UNB). Graduado em DiREITO E EM RELAC̣ões INTERnacionais PELA UNIVERSIDADE dO VALE dO ITAJAí. Advogado, consultor da UNESCO, E PESQUISAdOR do Centro de Pesquisa em Transportes da UNIVERSIDADE DE BRASÍLIA (CEFTRU/UNB).

\section{Fabiana de Oliveira Barbosa}

Brasília - DF - Brasil

Mestranda em TRansportes PELA UnIVERSIDADE de BRASília (UnB). conradodasilveiralagmail.com Graduada em Direito pelo UdF Centro Universitário. Pesquisadora do Centro de Pesquisa em Transportes DA UNIVERSIDADE DE BRASÍLIA (CEFTRU/UnB). 